\title{
Inhibition of allogeneic inflammatory responses by the Ribonucleotide Reductase Inhibitors, Didox and Trimidox
}

\author{
Mohammed S Inayat ${ }^{1}$, Ismail S El-Amouri ${ }^{1}$, Mohammad Bani-Ahmad', Howard L Elford ${ }^{2}$, Vincent S Gallicchio ${ }^{3}$, \\ Oliver R Oakley ${ }^{1 *}$
}

\begin{abstract}
Background: Graft-versus-host disease is the single most important obstacle facing successful allogeneic stem cell transplantation (SCT). Even with current immunosuppressive therapies, morbidity and mortality rates are high. Current therapies including cyclosporine A (CyA) and related compounds target IL-2 signaling. However, although these compounds offer great benefit, they are also associated with multiple toxicities. Therefore, new compounds with a greater efficacy and reduced toxicity are needed to enable us to overcome this hurdle.

Methods: The allogeneic mixed lymphocyte reaction (MLR) is a unique ex vivo method to study a drug's action on the initial events resulting in T-cell activation and proliferation, synonymous to the initial stages of tissue and organ destruction by T-cell responses in organ rejection and Graft-versus-host disease. Using this approach, we examined the effectiveness of two ribonucleotide reductase inhibitors (RRI), Didox and Trimidox, to inhibit T-cell activation and proliferation.

Results: The compounds caused a marked reduction in the proliferative responses of T-cells, which is also accompanied by decreased secretion of cytokines IL-6, IFN- $\gamma$, TNF- $\alpha$, IL-2, IL-13, IL-10 and IL-4.

Conclusions: In conclusion, these data provide critical information to justify further investigation into the potential use of these compounds post allogeneic bone marrow transplantation to alleviate graft-versus-host disease thereby achieving better outcomes.
\end{abstract}

\section{Introduction}

Graft-versus-host disease remains one the most frequent causes of morbidity in bone marrow transplantation. Current therapies address one of the six main immunosuppressive strategies in organ transplantation: proliferation, depletion, cytokines, costimulation, ischemia-reperfusion injury, and tolerance [1]. Many of these therapies are only successful in reducing acute organ rejection and do nothing for the long term survival of the graft, whilst others are associated with non-favorable side effects. The adverse effects of current treatments include hypertension, osteoporosis, hyperglycemia (steroids); hepatic dysfunction, thrombocytopenia, marrow suppression (azathioprine);

\footnotetext{
* Correspondence: oroakl1@uky.edu

'Department of Clinical Sciences, University of Kentucky, Lexington, KY 40536, USA

Full list of author information is available at the end of the article
}

limb paralysis and convulsion (cyclosporine). Therefore, the search continues for new therapeutic modalities that enable the long term survival of grafted tissue within the host with minimal side effects. To achieve this objective has led to the alternative therapeutic approach targeting key enzymes that control cell proliferation such as ribonucleotide reductase. The rate limiting step in DNA synthesis is the production of deoxynucleoside triphosphates (dNTPs) catalyzed by ribonucleotide reductase. Inhibition of ribonucleotide reductase results in reduced DNA synthesis and cell cycle arrest [2]. This has made ribonucleotide reductase inhibitors potentially attractive clinical agents for the treatment of numerous conditions characterized by excessive cell proliferation or inappropriate immune activation such as myeloproliferative disorders [3,4], psoriasis [5], sickle cell anemia [6,7], and HIV [8].
Ciomed Central

C 2010 Inayat et al; licensee BioMed Central Ltd. This is an Open Access article distributed under the terms of the Creative Commons Attribution License (http://creativecommons.org/licenses/by/2.0), which permits unrestricted use, distribution, and reproduction in any medium, provided the original work is properly cited. 
Didox and Trimidox are polyhydroxyphenyl hydroxamic acid derivatives that are more potent inhibitors of ribonucleotide reductase than the current clinical compound, hydroxyurea (HU), which targets ribonucleotide reductase $[9,10]$. They have been evaluated in several animal models to compare their actions to that of $\mathrm{HU}$. These studies evaluate their use in animal models of HIV [9], sickle cell disease [11], and several malignancies [12] and have shown that these compounds have greater therapeutic effectiveness and lower toxicity than HU. Given the potent efficacy and low toxicity of Didox and Trimidox in animal models, and the potential utility of ribonucleotide reductase inhibitors as cytostatic agents that may influence immune cell activation, we investigated the anti-inflammatory ability of Didox and Trimidox as a therapeutic approach to improve transplant success. Our findings clearly demonstrate that these compounds inhibit both $\mathrm{T}$-cell proliferation and cytokine production following anti-CD3e stimulation as well as in allogeneic mixed lymphocyte reactions. Not only does this have implications for monotherapy, but it has been previously shown that ribonucleotide reductase inhibitors, specifically HU are able to potentiate other drugs in a combination drug therapy [13]. The studies reported here should promote further examination into the use of Didox and Trimidox as potentiators of current therapies, thereby reducing the required dose level and associated side effects to achieve similar efficacy.

\section{Materials and methods Drug Treatment}

Didox and Trimidox were synthesized and kindly provided by Dr Howard Elford, Molecules for Health (Richmond, VA). All of the compounds were dissolved in $0.9 \%$ sterile saline solution then filtered through a $0.45 \mu \mathrm{m}$ syringe top filter and stored at $4^{\circ} \mathrm{C}$ in the dark for a maximum of 1 week.

\section{Mice}

Female C57BL6, BALB/c mice aged 6-8 weeks were purchased from Harlan (Indianapolis, ID) and B10.D2 mice were obtained from The Jackson Laboratories (Bar Harbor, ME). They were housed in micro-isolator cages in temperature and humidity controlled environment and were given Purina Lab Chow and water ad libitum. Mice were quarantined for one week post arrival as per University of Kentucky Division of Lab Animal Research (DLAR) Standard Operating Procedures (SOP). All protocols and procedures used were approved by the University of Kentucky Institutional Animal Care and Use Committee (IACUC) prior to initiation of research.

\section{Cell lines}

CCL-1972 mouse embryonic fibroblast (MEF) cells were obtained from the American Type Tissue Culture Collection (ATCC: Manassas, VA). They were propagated in T75 canted neck culture flasks in Dulbecco's Modified Eagles Medium (DMEM: Gibco BRL, Grand Island, N.Y) supplemented with $10 \%$ fetal bovine serum (Sigma Chemical Co, St. Louis, USA) and 1\% Penicillin/Streptomycin (Gibco BRL. 10,000 units per $\mathrm{ml}$ penicillin $+10,000 \mathrm{mg} / \mathrm{ml}$ streptomycin sulphate in $0.85 \%$ saline), and maintained in an incubator (Queue: Cell culture incubator) at $37^{\circ} \mathrm{C}$ and $5 \%$ carbon dioxide humidified atmosphere.

\section{T-cell Isolation}

Mice were killed and the spleens were aseptically excised and placed into a Petri dish containing $3 \mathrm{ml}$ of $2 \mathrm{mg} / \mathrm{ml}$ Collagenase I (Gibco), cut into small pieces and incubated for 60 minutes at $37^{\circ} \mathrm{C}$. The whole spleen suspension was then gently pushed through a $70 \mu \mathrm{m}$ nylon filter (Falcon, BD, Franklin Lakes, NJ). The filtrate was washed twice in $15 \mathrm{ml}$ of HBSS (Gibco), then resuspended in $400 \mu \mathrm{l}$ of degassed MACS buffer (PBS pH 7.2, $2 \mathrm{mM}$ EDTA and 0.5\% BSA) per spleen. T-cells were separated using MACS LS separation columns as per manufacturer's instructions. Magnetic Labeling: (Pan T-Cell Isolation Kit, Miltenyi Biotec Inc, Auburn, CA) $100 \mu \mathrm{l}$ of Biotin-antibody cocktail was added per spleen, mixed and incubated for 10 minutes at $4{ }^{\circ} \mathrm{C}$. Then, $300 \mu \mathrm{l}$ of buffer and $200 \mu \mathrm{l}$ of anti-biotin Microbeads were added and incubated for a further 15 minutes at $4^{\circ} \mathrm{C}$. The cells were then washed in $5 \mathrm{ml}$ buffer at $1200 \mathrm{RPM}, 4^{\circ} \mathrm{C}$ for 10 minutes. Finally, the pellet was resuspended in $1 \mathrm{ml}$ of buffer. Magnetic Separation: The LS column was prepared by pre-rinsing with $3 \mathrm{ml}$ of buffer. The labeled suspension was then gently added to the column and the unlabelled effluent collected followed by 4 washes of $3 \mathrm{ml}$ each to increase T-cell yield.

\section{T-Cell proliferation assay}

Cell proliferation and viability were determined using WST-1 colorimetric assay system which is based on the cleavage of tetrazolium salt by mitochondrial dehydrogenase in viable cells (Roche Applied Sciences, Penzberg, Germany). A concentration of $5 \times 10^{4}$ cells per well was added to a 96 well flat bottom plate (Costar, Corning, NY) pre-coated with immobilized anti-CD3 $\varepsilon$ (with or without drug treatment) and incubated at $37^{\circ} \mathrm{C}$ and $5 \% \mathrm{CO}_{2}$. Proliferation was determined as per the manufacturer's instructions at 24, 48, 72 and 96 hours post treatment. 


\section{Cytokine Analysis}

T-cells $\left(1 \times 10^{5}\right.$ per well) were incubated at $37^{\circ} \mathrm{C}$ and $5 \%$ $\mathrm{CO}_{2}$ in 96-well plates (Costar, Corning, NY) coated with anti-CD3 $\varepsilon$ monoclonal antibodies (eBioscience, San Diego, CA). Culture supernatants were taken at 24 and 48 hour time points; the supernatants were spun free of cells and aliquots were frozen at $-80^{\circ} \mathrm{C}$. Levels of cytokine secretion (IL-2, IL-4, IL-6, IL-10, IL-12p70, IL-13, IFN- $\gamma$ and TNF- $\alpha$ ) were analyzed with the Searchlight multiplex assay system (Pierce Biotechnology Inc, Woburn, MA). Briefly, Custom 96 well culture plates (Costar) were manufactured which contained target capture antibodies as indicated above. $50 \mu \mathrm{l}$ of the supernatant was then added to each well for 1 hour, followed by three washes and the addition of biotinylated secondary antibodies for 30 minutes. The wells were then washed again and streptavidin-horseradish peroxidase (SA-HRP) conjugate was added followed by the addition of SuperSignal ${ }^{\circ}$ ELISA Femto chemiluminescent substrate. The luminescence was then detected and analyzed using a cooled charge-coupled device imager (Pierce Biotechnology Inc).

\section{Mixed Lymphocyte Reaction}

$\mathrm{T}$-cell depleted stimulator cells were obtained from splenocytes from BALB/c mice by magnetic bead purification (Miltenyi Biotec). The cells were collected in RPMI 1640 growth media (Gibco) supplemented with 10\% fetal bovine serum (Sigma), $50 \mu \mathrm{M}$ 2-mercaptoethanol (Sigma) and 1\% penicillin streptomycin (Gibco) and irradiated with 3000 rads of $\gamma$-radiation form a Cs-137 source.

Responder T-cells were isolated as previously described (Miltenyi Biotec) from C57BL6 (Major antigen mismatch) mice and B10.D2 (Minor antigen mismatch) mouse strains. A total of $2 \times 10^{5}$ responder cells were combined with $4 \times 10^{5}$ stimulator cells per well in 96 well flat bottom plates (Costar) and incubated at $37^{\circ} \mathrm{C}$ and 5\% $\mathrm{CO}_{2}$. T-cell culture media, RPMI 1640 (Gibco) containing $10 \%$ fetal bovine serum (Sigma), $50 \mu \mathrm{M}$ 2-mercaptoethanol (Sigma) and 1\% penicillin streptomycin (Gibco) was supplemented with either Didox or Trimidox from $25 \mu \mathrm{M}-100 \mu \mathrm{M}$ or PBS and the MLRs were analyzed in triplicate on day 6 .

\section{Statistical analysis}

When applicable, results were subjected to statistical analysis. Data were analyzed and plotted using SigmaPlot version 10.0 (Systat software Inc., Chicago, IL). On graphs, error bars represent one standard error $( \pm$ SE) around the average of data per group. To determine the statistical significance between groups, ANOVA was performed followed by post-hoc analysis using Bonferroni method. Data that failed normality testing was normalized using log transformation. $p$ values $<0.05$ were considered significant.

\section{Results \\ Didox and Trimidox inhibit T-cell proliferation in CD3E stimulated cultures}

To determine the influence of Didox and Trimidox on $\mathrm{T}$-cell proliferation, we first studied the effects of the

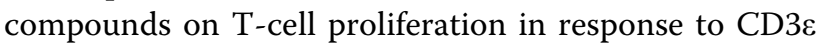
stimulation. Untreated control cultures did not show detectable proliferation throughout the experiments. Following stimulation, proliferation was detected in stimulated control cultures at 48 hours. The control cultures continued to proliferate rapidly until the last time point assayed at 96 hours post stimulation (Figure 1). Didox (Figure 1A) treatment at the lowest concentration $(25 \mu \mathrm{M})$ reduced $\mathrm{T}$-cell proliferation by approximately $90 \%$ at 96 hours post stimulation, and proliferation was undetectable when treated with $50 \mu \mathrm{M}$. Trimidox (Figure $2 \mathrm{~B}$ ) at $25 \mu \mathrm{M}$ inhibited proliferation by approximately $65 \%$ compared to stimulated control at 96 hours post stimulation and completely blocked proliferation at $50 \mu \mathrm{M}$ concentration.

\section{Suppression of T-cell proliferation by Didox and Trimidox} is not due to the cytotoxic effects of the treatment

To determine if the lack of proliferation was a result of the toxicity of the compounds, we studied the effects of drug treatment on cell viability. In the proliferation studies, we observed that $50 \mu \mathrm{M}$ of Didox or Trimidox was sufficient to completely block T-cell proliferation (Figure 1). Figure 2A. shows cell viability of B10.D2 and C57BL6 $\mathrm{T}$-cells in response to Didox treatment. The results indicate that C57BL6 cells are more tolerant to the treatment than B10.D2 cells. Even so, Didox treatment only reduced cell viability in the B10.D2 cells by $20 \%$ at 100 $\mu \mathrm{M}$. The C57BL6 cells were more tolerant to the compound and had a minimal (5\%) reduction in cell viability at the highest concentration used $(100 \mu \mathrm{M})$. Figure $2 \mathrm{~B}$ shows cell viability in response to Trimidox treatment. We observed an approximate $15 \%$ reduction in cell viability at the minimal effective dose $(25 \mu \mathrm{M})$. Cell viability in both B10.D2 and C57BL6 was decreased to less than $50 \%$ when cells were exposed to $100 \mu \mathrm{M}$ concentrations.

\section{Suppression of anti CD3\& induced cytokine production in} T-cell cultures by Didox and Trimidox

We next studied the effects of Didox and Trimidox on cytokine production. As mentioned previously, many current therapies target cytokine signaling or production, in particular the CyA derivatives inhibit signaling through IL-2. T-cell cultures stimulated with antiCD3 $\varepsilon$ were tested for cytokine activity using the 

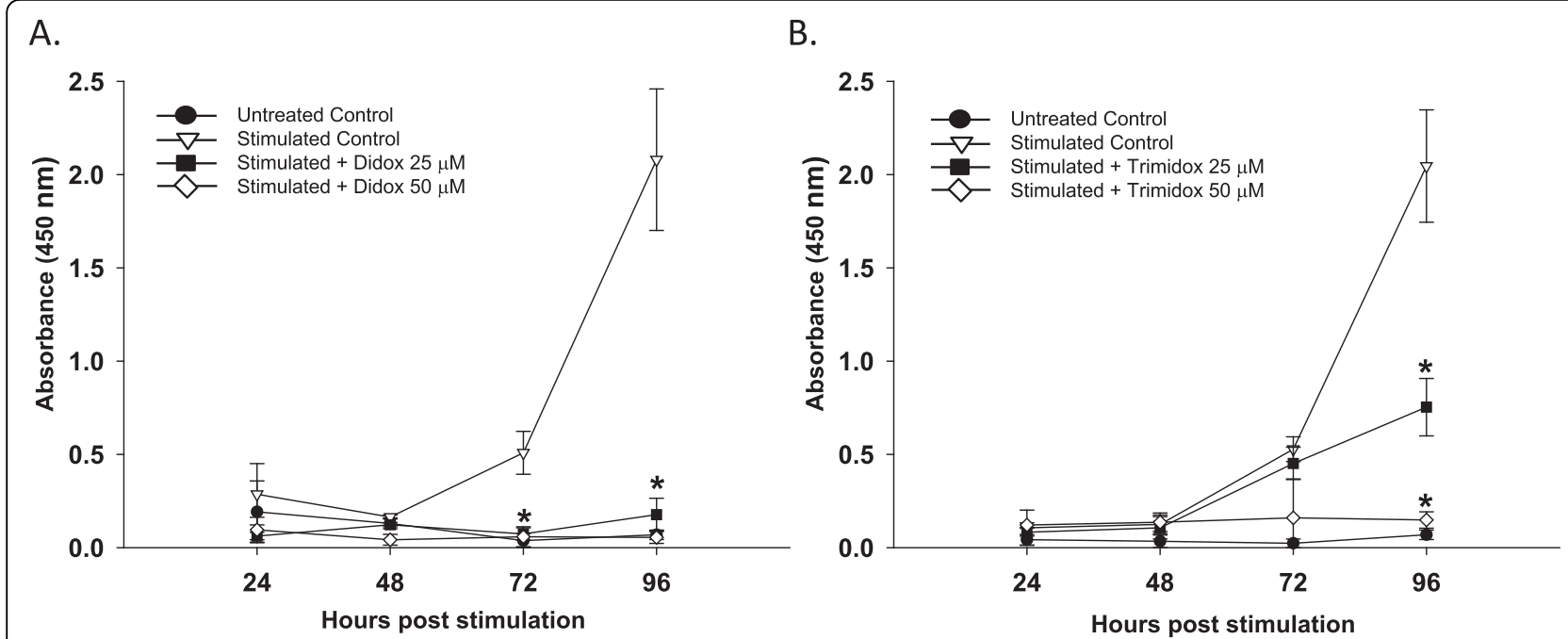

Figure 1 Inhibition of proliferation of T-cell obtained from B10.D2 mice spleens. Briefly, $5 \times 10^{4} \mathrm{~T}$-cells per well were purified and seeded in 96 well sterile plates pre-coated with PBS or anti CD3 $\varepsilon$ antibodies $(5 \mu \mathrm{g} / \mathrm{ml})$. Either PBS or several concentrations of Didox or Trimidox (25 $\mu \mathrm{M}$ and $50 \mu \mathrm{M}$ ) was added to RPMl 1640 growth media supplemented with 10\% fetal bovine serum, $50 \mu \mathrm{M}$ 2-Mercaptoethanol and 1\% penicillin streptomycin. The plates were then incubated at $37^{\circ} \mathrm{C}$ and $5 \% \mathrm{CO}_{2}$ for $24,48,72$ or 96 hours, after which spectrophotometric quantification of cell growth and viability was determined. The results shown represent data obtained in triplicate from two independent experiments. (A) Treated with Didox (B) Treated with Trimidox. Values shown (mean \pm SD) represent data obtained in triplicate from two independent experiments. ${ }^{*}$ indicate a significant difference compared to anti CD3 $\varepsilon$ stimulated. ( $p<0.05$, ANOVA + the Bonferroni test).

Searchlight multiplex assay at 24 and 48 hours post stimulation. We tested both B10.D2 (Figure 3A) and C57BL6 (Figure 3B) cells independently. As expected, the unstimulated $(\mathrm{NC})$ (no anti-CD3e treatment) cells showed minimal cytokine production. However, in as little as 24 hours, both C57BL6 and B10.D2 cells responded to anti-CD3e (AC) by increasing secretion of IFN- $\gamma$, IL-2 and IL-6. In contrast, cells treated simultaneously with Didox and anti-CD3e demonstrated a dose response inhibition of cytokine production at 24 or 48 hours post stimulation compared to the activated controls $(\mathrm{AC})(p<0.02)$.
A.

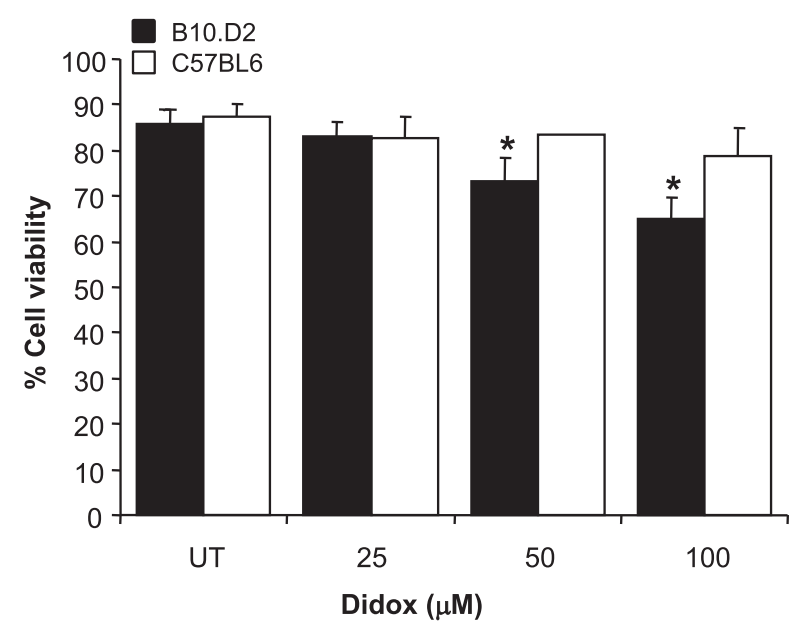

B.

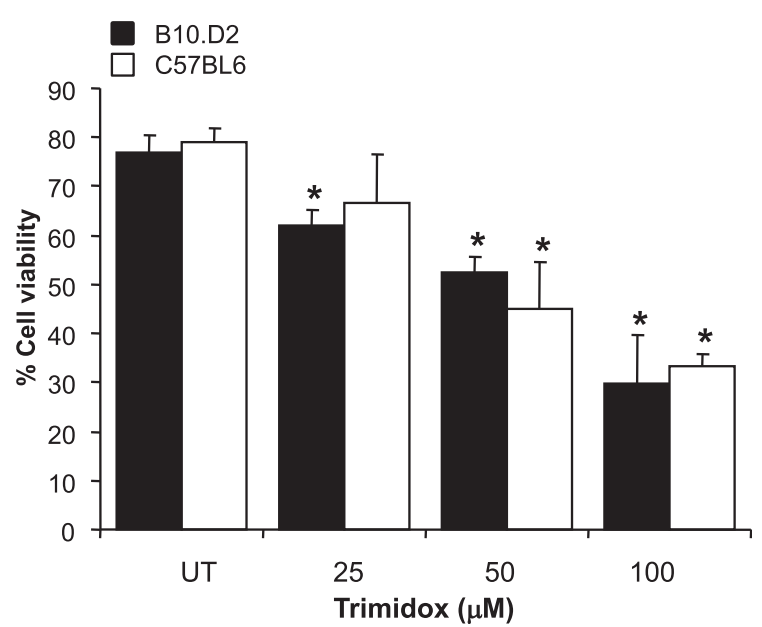

Figure 2 Cellular toxicity of Didox and Trimidox in T-cells from C57BL6 and B10.D2 mouse strains. Briefly, $1 \times 10^{5}$ cells per well were seeded in 96 well culture plates in RPMI 1640 supplemented with 10\% fetal bovine serum and 1\% penicillin streptomycin and 2-

mercaptoethanol, containing PBS or concentrations of Didox or Trimidox from $25 \mu \mathrm{M}-100 \mu \mathrm{M}$. The cells were then incubated at $37^{\circ} \mathrm{C}$ and $5 \%$ $\mathrm{CO}_{2}$ for 4 days. After this, percentage of viable cells of (A) Didox and (B) Trimidox was determined for each drug dose. ${ }^{*}$ indicates a significant difference compared to PBS treated (UT). ( $p<0.05$, ANOVA + the Bonferroni test; $\mathrm{n}=3)$. 


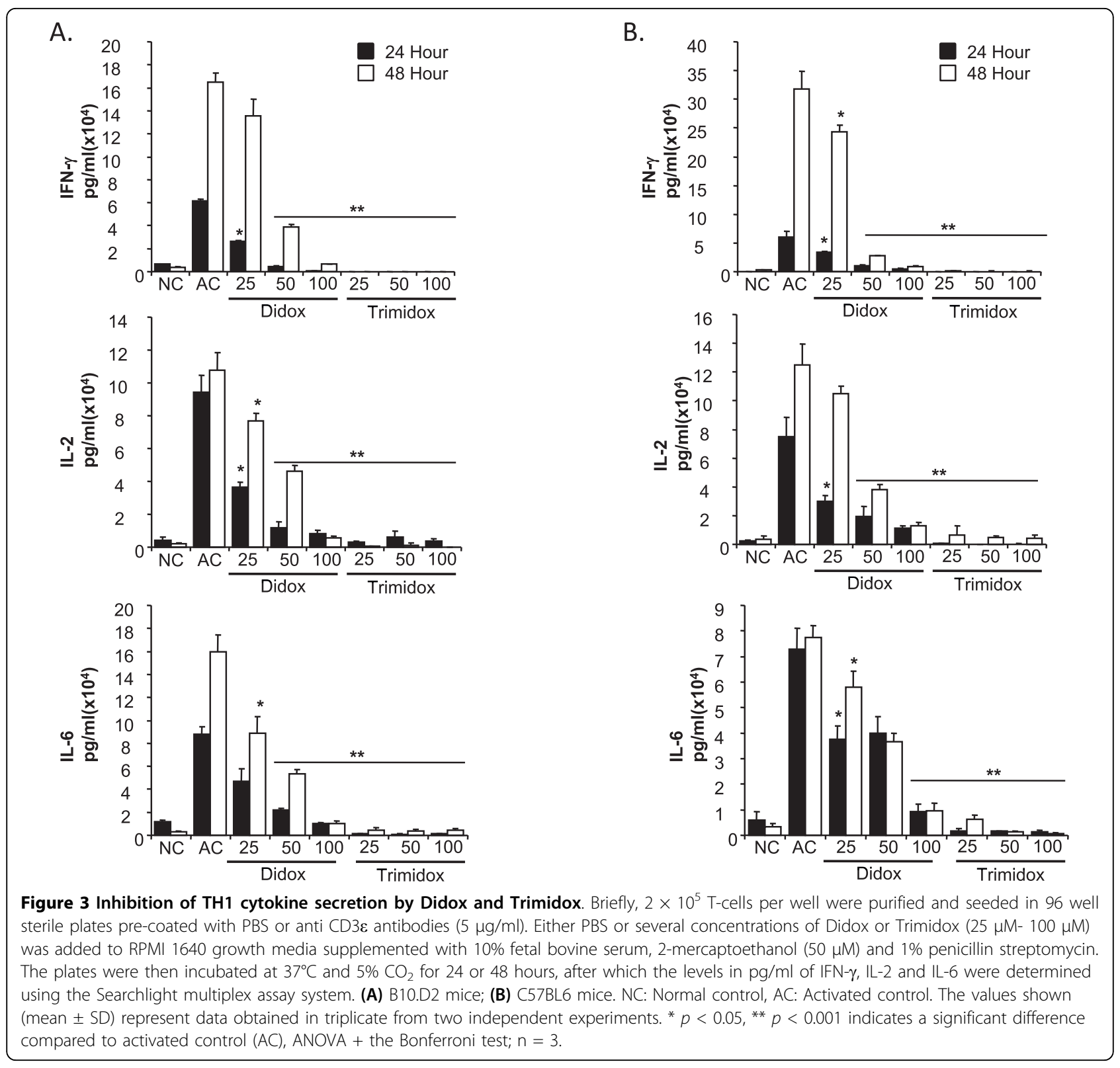

We observed an even greater inhibition of cytokine production by Trimidox following anti-CD3 $\varepsilon$ stimulation of T-cell cultures in both B10.D2 and C57BL6 mice. The production of IFN- $\gamma$ was below detectable levels in both cell types at either 24 or 48 hours. The production of IL-2 in both cell types was comparable to that of unstimulated cells of the same strain; this pattern was also true for IL- 6 production.

We also examined the production of several Th2 type cytokines IL-4, IL-13 and IL-10 (Figure 4). Normal control cell supernatants contained minimal levels of IL-4, IL-13 and IL-10. Following stimulation with anti-CD3e, cultures rapidly produced increased levels of Th2 type cytokines at 24 hours post stimulation that further increased at 48 hours post stimulation. Treatment with Trimidox, even at the lowest dose $(25 \mu \mathrm{M})$, reduced the levels of IL-4 and IL-10 to the lower detection limits. Interestingly, Trimidox treatment in either B10.D2 or C57BL6 mice reduced levels of IL-13 to levels comparable to normal controls (NC). Didox treatment demonstrated a dose dependant decrease in cytokine levels for IL-4, IL-10 and IL-13.

The effects of Didox and Trimidox on Allogeneic MLR

The following experiments were performed to analyze the effects of Didox and Trimidox in the complex interaction of allo-recognition and activation of responder $\mathrm{T}$ cells to both major (Figure 5A) and minor (Figure 5B) 


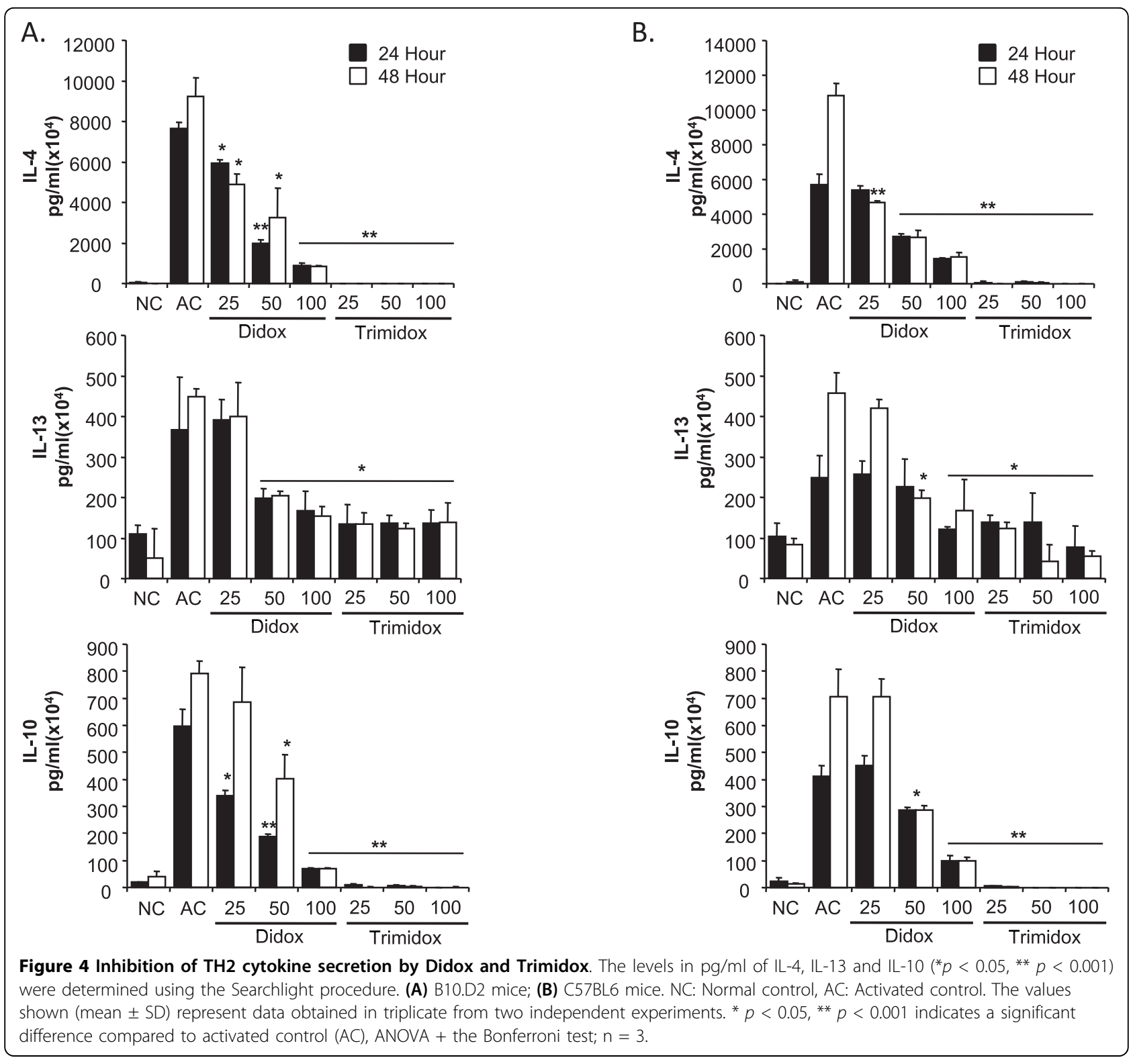

mismatched antigens. In the first set of experiments, C57BL6 lymphocytes were stimulated with irradiated BALB/c stimulators. Didox and Trimidox were added at $25 \mu \mathrm{M}, 50 \mu \mathrm{M}$ and $100 \mu \mathrm{M}$ following initiation of the cultures. As shown in Figure 5A., untreated cultures demonstrated an increase in $\mathrm{T}$-cell proliferation. The addition of Didox or Trimidox at either $25 \mu \mathrm{M}$ or 50 $\mu \mathrm{M}$ caused $40-45 \%$ inhibition of proliferation. The addition of $100 \mu \mathrm{M}$ of Didox or Trimidox caused a $75-80 \%$ inhibition of proliferative responses. The second set of experiments used T-cells from B10.D2 mice as the responders and irradiated non-T-cells from BALB/c mice as the stimulators. Figure $5 \mathrm{~B}$. shows the inhibition of proliferative responses by both Didox and Trimidox in a dose dependant manner. Here we show a $20-25 \%$ inhibition by both drugs at $25 \mu \mathrm{M}$, a $45-50 \%$ inhibition by both drugs at $50 \mu \mathrm{M}$, and a $70-75 \%$ inhibition by both drugs at $100 \mu \mathrm{M}$.

\section{Didox and Trimidox inhibit cytokine production during the MLR}

In an extension of the anti-CD3 $\varepsilon$ studies in which we observed an inhibition of cytokine production, we performed similar Searchlight multiplex analysis on 6 day culture supernatants from either major or minor antigen mismatched MLRs. Figure 6 shows the results for IFN- $\gamma$, TNF- $\alpha$, IL-2, and IL- 6 cytokine levels from cell culture supernatants in response to minor and major antigen 


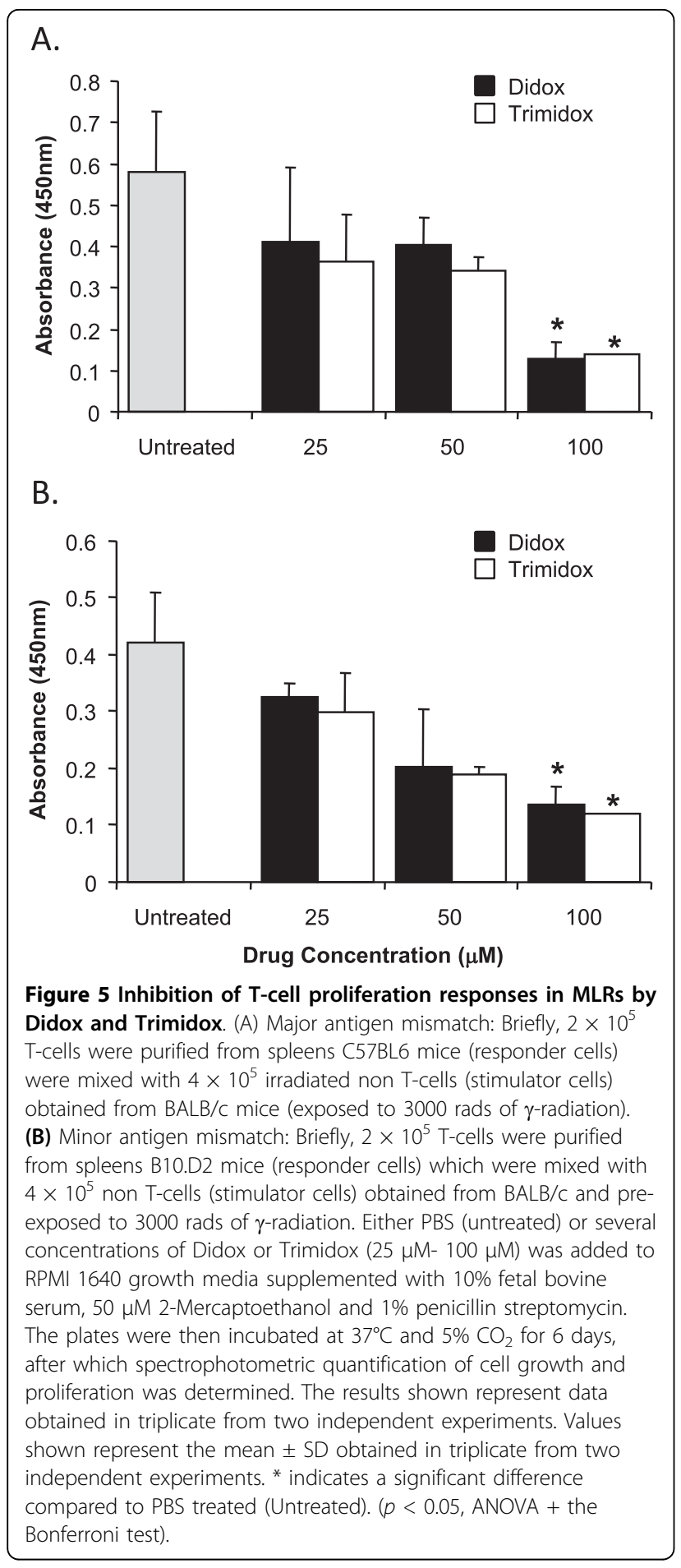

stimulation. The base line production of cytokines is represented in each graph by the normal control (NC), unstimulated responder cells and untreated activated control (AC). The minor MHC antigen stimulated cultures showed only a minimal increase in cytokine production, ranging from only a $25 \%$ increase in IFN- $\gamma$ to a $250 \%$ increase in IL-2. In sharp contrast, however, the major antigen stimulation resulted in a 78.4 fold increase in IFN- $\gamma$ expression when compared to the normal control group (Figure 6). These data clearly demonstrate the inflammatory effect of major MHC mismatched antigens to stimulate a potent cytokine response for all four cytokines shown. A similar trend in the secretion of IL-2 was observed, with only a 2 -fold increase in response to minor antigens and $>6$ fold increase with the major MLR (Figure 6). An increase in IL-6 production was seen in both the major MLR and minor MLR when compared to the normal controls.

Treatment with Didox or Trimidox was able to inhibit MLR induced cytokine production in a dose dependent manner. Trimidox inhibited cytokine production to background levels at a dose of $25 \mu \mathrm{M}$ for IL-2, $50 \mu \mathrm{M}$ for IFN- $\gamma, 100 \mu \mathrm{M}$ for TNF- $\alpha$ and $100 \mu \mathrm{M}$ for IL-6. In contrast, a higher dose of Didox $(100 \mu \mathrm{M})$ was needed to inhibit IFN- $\gamma$ and IL-2 production to levels comparable to NC.

As shown in Figure 7, major antigen mismatched MLRs resulted in a rapid upregulation of the Th2 derived cytokines, IL-13, IL-4 and IL-10. In the minor antigen MLRs, a significant increase was only detected in the production of IL-4, which was quenched by the lowest dose $(25 \mu \mathrm{M})$ of either Didox or Trimidox. NC (unstimulated responder cells) had minimal levels of cytokine production. Didox inhibited cytokine production in a dose dependant manner for IL-13, IL-10 and IL-4, with the $100 \mu \mathrm{M}$ dose of Didox inhibiting cytokine levels comparable to that in NC. Trimidox inhibited cytokine production more vigorously than Didox with a dose of $25 \mu \mathrm{M}$ inhibiting IL-10, IL-13, and IL-4 by approximately $40 \%, 60 \%$ and $90 \%$ respectively. Levels of cytokines were reduced to or below that of NC by treatment with a $50 \mu \mathrm{M}$ dose. Together, these data demonstrate the ability of the ribonucleotide reductase inhibitors, Didox and Trimidox, to act as inhibitors of inflammatory responses by both inhibiting the proliferation of T-cells and the production of cytokines.

\section{Discussion}

In this study, we determined the effect of Didox and Trimidox on the proliferative response of $\mathrm{T}$-cells. Although ribonucleotide reductase inhibitors, specifically $\mathrm{HU}$, have been used extensively to synergize the actions of other compounds, such as the combination of $\mathrm{HU}$ with didanosine in the treatment of HIV $[14,15]$, recent studies have identified other potential applications based on their cytostatic properties [16]. The results of this report demonstrate the ability of Didox and Trimidox to function as cytostatic compounds by inhibiting T-cell proliferation that occurs as a consequence of SCT or solid organ transplantation. In addition, the experiments presented here demonstrate that Didox and Trimidox 


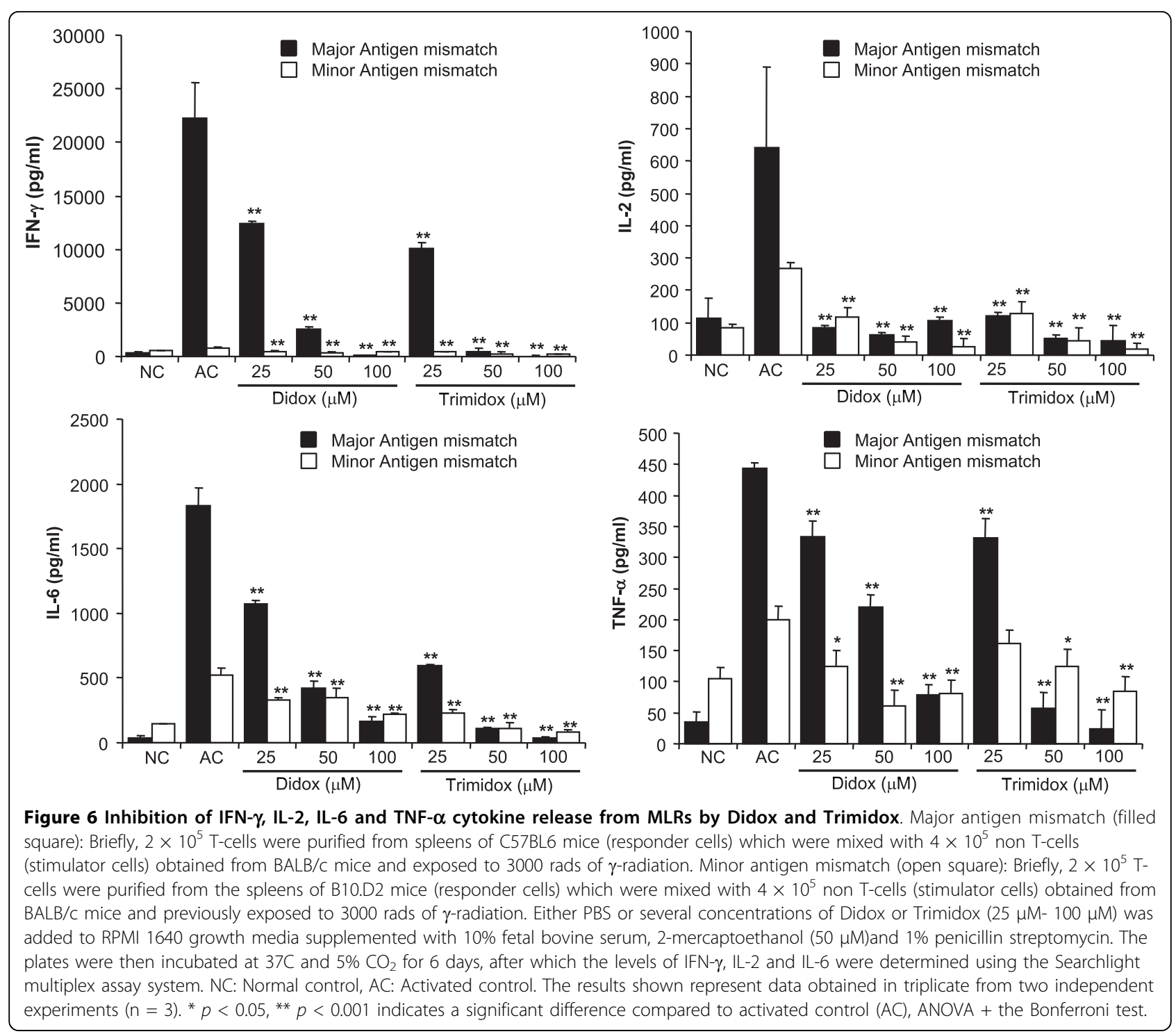

inhibit the proliferation of not only T-cells following anti-CD3\& stimulation, but also in MLRs. Previous studies have identified $\mathrm{T}$-cell proliferation, cytokine secretion, and the resulting increased expression of chemokines as crucial events following solid organ or stem cell transplant (SCT). By specifically targeting these responses, these compounds have the potential to limit graft rejection or graft-versus-host disease $[17,18]$.

The process of graft rejection is a complicated yet well orchestrated event; the precise mechanisms are still not completely understood. It is known that T-cells alone are not sufficient for graft rejection, that cytokines are required and that rejection is driven by a Th1-type pattern of immune activation [19], and as such, a switch to a predominantly Th2-type pattern can be beneficial to graft survival at the cost of increased opportunistic infections.
Previous work has shown that IL-2, IL-6, TNF- $\alpha$ and IFN- $\gamma$ secretion is associated with acute graft-versushost disease [20,21], whilst increased circulatory levels of IL-6 have been associated with chronic graft-versushost disease [22]. More recently, Mohty review the clinical significance of Th1 cytokines in both amplification of donor responses and direct cytotoxicity [23]. Hoping to alleviate these detrimental events, we demonstrate here, the ability of these compounds to inhibit the secretion of the crucial cytokines, IL-2, IL-6, TNF- $\alpha$ and IFN- $\gamma$ thereby reducing the collateral damage caused by the direct actions of these cytokines, whilst decreasing the proliferative capacity of the T-cells. The differential inhibition of cytokines and T-cell proliferation may be an indication that the two compounds, Didox and Trimidox may actually be functioning by two distinct mechanisms. The first as an inhibitor of ribonucleotide 

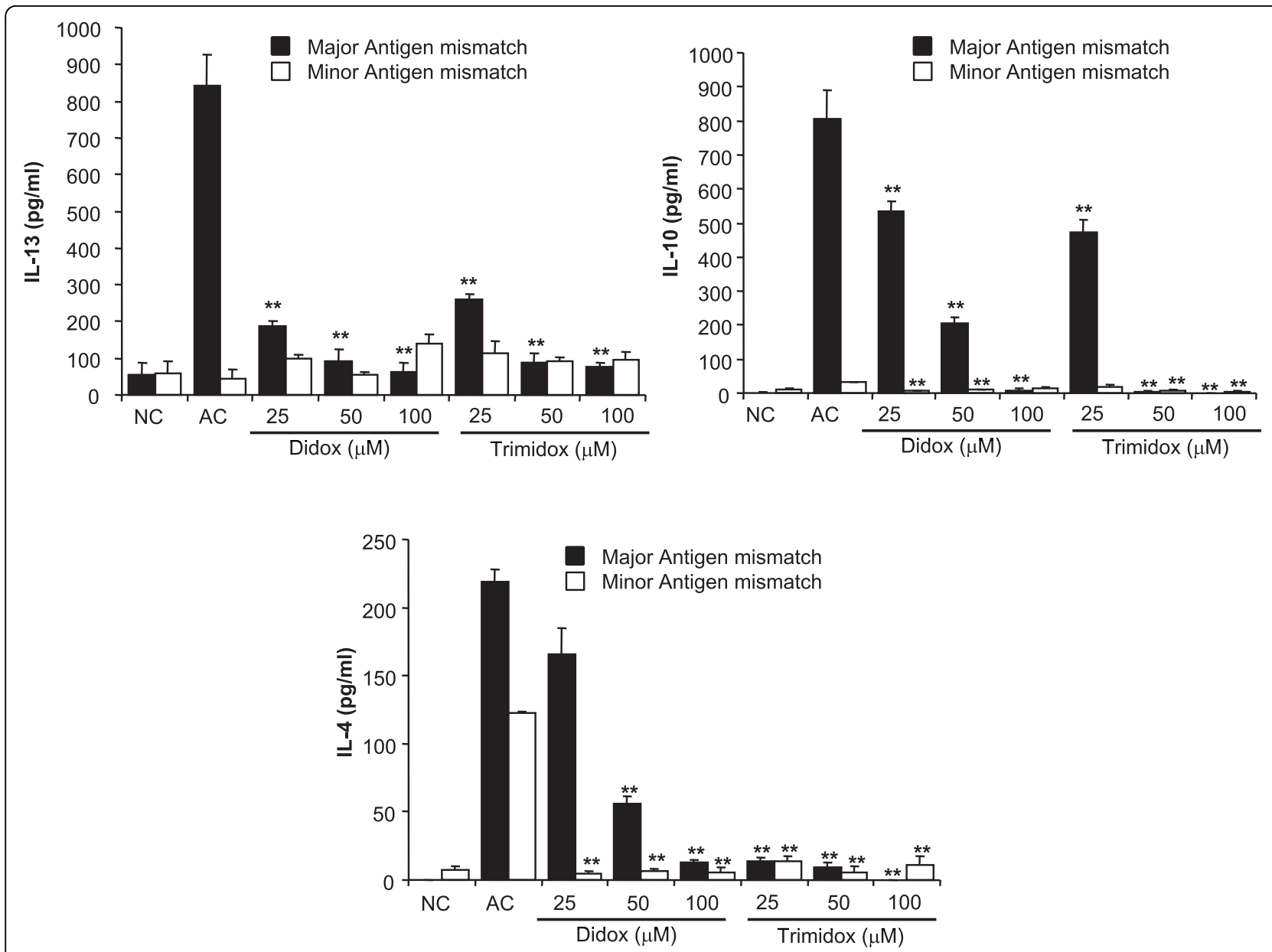

Figure 7 Inhibition of IL-13, IL-10 and IL-4 cytokine release from MLRs by Didox and Trimidox. The levels of IL-13, IL-10 and IL-4 were determined using the Searchlight multiplex assay system from minor (open square) or major (filled square) mixed lymphocyte reactions. NC: Normal control, AC: Activated control. The results shown represent data obtained in triplicate from two independent experiments $(n=3-6)$. ${ }^{*} p<0.05,{ }^{* *} p<0.001$ indicates a significant difference compared to activated control (AC), ANOVA + the Bonferroni test.

reductase, with its effects resulting in a reduction of T-cell proliferation; the second mechanism may be acting at another level, directly reducing inflammatory cytokine levels. Previous studies show that both Didox and Trimidox directly inhibit NF $\kappa \mathrm{B}$ phosphorylation at concentrations comparable to this study [24]. Therefore, the second mechanism, inhibiting cytokine levels may be a result of Didox and Trimidox inhibition of NF $\kappa \mathrm{B}$.

The concept of using drugs to inhibit T-cell proliferation is not a new one; however, a major drawback of this approach has been the concurrent inhibition in any residual anti-tumor, or graft versus leukemia (GVL) effect of lymphocytes that remain. The beneficial effects of GVL responses have been well documented [25-28]. This GVL effect is one that is most notably seen in allogeneic as opposed to autologous bone marrow transplants and is dependent on the genetic mismatch between graft and recipient. However, in order for this retained GVL effect to be effective, T-cells populations must also be able to activate and proliferate in response to antigen, whether it is allo-antigen (major or minor), tumor-antigen, tumor-associated antigen or a combination of all three.

Recent publications have demonstrated certain ribonucleotide reductase inhibitors function as virostatics $[8,29]$ and that this effect may be an additional benefit. More recently, the immune modulatory effects of $\mathrm{HU}$ have been postulated. Lori et al described the "predatorprey" hypothesis [29] where the cytostatic effects of $\mathrm{HU}$ would force T-lymphocytes into becoming quiescent, thus becoming less prone to HIV infection. The overall effect is fewer numbers of infected cells and reduced viral loads and ultimately more effective control by host immune responses. Benito et al [30] described the antiproliferative effects of $\mathrm{HU}$ on T-cells without diminishing their cellular activation. 
In addition to Didox and Trimidox being considered for use as anti-proliferative agents, current research has indicated that they are also successful as anti-tumor agents. Raje, et al [31] demonstrates that Didox specifically induces a caspase-dependant cytotoxicity in multiple myeloma (MM) cells. They demonstrate that not only does Didox induce apoptosis in MM cells, but that this is accompanied by a down-regulation of several other genes including bcl-2, bclx1, and XIAP as well as a reduction in both expression and protein levels of M1 subunit of ribonucleotide reductase. They also demonstrated a myeloma-specific down-regulation of RAD 51 homologue, an active gene in DNA repair. The authors conclude that Didox acts on both DNA synthesis and repair.

In contrast to studies using HU [32], Didox and Trimidox also inhibited the production of Th2 type cytokines. These cytokines are known to suppress many pro-inflammatory cytokines and chemokines. In the transplant scenario, upregulation of these cytokines may be important in the generation of humoral responses. The differential inhibition of Th1 cytokines by HU results in a net increase in Th2 type cytokines, thus further lowering the immune response and increasing the potential for opportunistic infections. Here we show that Didox and Trimidox inhibit both Th1 and Th2 cytokines possibly leaving the Th1:Th2 balance intact although at a reduced level. The in vivo implications of these data are important due to many factors. The secretion of IFN- $\gamma$ in the post transplant setting is important in both direct cellular damage to host tissues and also in the stimulation of cell mediated responses [33]. Increased levels of IL-6 have also been found to be a negative predictor of graft survival in numerous transplant scenarios $[34,35]$. The widespread effect of IL-2 on $\mathrm{T}$-cell proliferation has been well documented and thus serves as a target for many of the current immunosuppressive therapies. Our data implies that Didox and Trimidox can be important tools to inhibit the proliferation of $\mathrm{T}$-cells in the transplant setting by both inhibiting $\mathrm{T}$ cell proliferation and reducing detrimental cytokine secretion. However, the question remains whether these treatments would impair the normal host defenses against microbial insults. Weinberg [32] suggests that the action of ribonucleotide reductase inhibitors would not impair immunological responses to opportunistic pathogens as their actions are limited to stimulated lymphocytes and that unstimulated PBMCs are unaffected.

Finally, one of the major side effects of current ribonucleotide reductase inhibitor treatment is the potential for myelotoxicity, an unfavorable side effect post transplant. These effects can be directly damaging to the bone marrow by preventing the mobilization of stems cells and thus affecting the self-renewal capacity of the bone marrow as a whole. As such, this myelotoxicity can persist for many years following cessation of treatment further impairing future treatments. However, previous work has shown the improved antiviral effects of Didox and Trimidox with a limited myelosuppressive effects [10] compared to HU, which indicates that, unlike HU, myelotoxicity would not be as problematic when using Didox or Trimidox.

To summarize, allogeneic SCT results in the up regulation of a plethora of chemokines, cytokines, and transcription factors which culminate in the homing/ localization and emergence of host reactive $\mathrm{T}$-cells resulting in graft-versus-host disease in the recipient [36,37]. These studies demonstrate that both Didox and Trimidox, at doses achievable in vivo, have anti-proliferative effects on $\mathrm{T}$-cells in response to allo-antigens and downregulate crucial cytokine secretion associated with graft versus host disease. These findings indicate that Didox and Trimidox act in a multifaceted manner, and as such, would be suitable candidates for further evaluation in animal models of solid organ transplant, graft-versus-host disease and autoimmunity.

\section{Abbreviations}

IFN- $\gamma$ : interferon-gamma; MLR: mixed lymphocyte reaction; RRI: ribonucleotide reductase inhibitor; CyA: cyclosporine A; GVHD: graft-versushost disease.

\section{Acknowledgements}

We are very grateful to Dr. Beth A. Garvy and Yajarayma Tang-Feldman for their critical review of the manuscript and helpful discussions. This work was supported by a National Institutes of Health grant: 1R15HD065605-01 (O.R.O.).

\section{Author details}

${ }^{1}$ Department of Clinical Sciences, University of Kentucky, Lexington, KY 40536, USA. ${ }^{2}$ Molecules for Health, Inc., Richmond, VA 23219, USA. ${ }^{3}$ Departments of Biological Sciences and Public Health Sciences, Clemson University, Clemson, SC 29634, USA.

\section{Authors' contributions}

$\mathrm{Ml}$ participated in the design of the experiments, carried out the T-cell isolation, T-cell proliferation, cytokine analysis and MLR and analysis of the data. IE participated in the T-cell proliferation assays and statistical analysis. MB participated in the T-cell proliferation assays. HE supplied the

compounds Trimidox and Didox and participated in the determination of the in vitro dosing. VG assisted in drafting the manuscript. OO conceived the study, directed its design and coordination and drafted the manuscript. All authors read and approved the final manuscript.

\section{Competing interests}

HE is President and a shareholder of Molecules for Health (MFH) and thereby has a financial interest in Didox or Trimidox therapeutic potential. All other authors declare that they have no competing interests.

Received: 5 April 2010 Accepted: 18 August 2010

Published: 18 August 2010

\section{References}

1. Hong JC, Kahan BD: Immunosuppressive agents in organ transplantation: past, present, and future. Seminars in nephrology 2000, 20:108-25.

2. Yarbro JW: Mechanism of action of hydroxyurea. Seminars in oncology 1992, 19:1-10. 
3. Kennedy BJ: The evolution of hydroxyurea therapy in chronic myelogenous leukemia. Seminars in oncology 1992, 19:21-6.

4. Kiladjian JJ, Rain JD, Bernard JF, Briere J, Chomienne C, Fenaux P: Longterm incidence of hematological evolution in three French prospective studies of hydroxyurea and pipobroman in polycythemia vera and essential thrombocythemia. Seminars in thrombosis and hemostasis 2006, 32:417-21.

5. Smith $\mathrm{CH}$ : Use of hydroxyurea in psoriasis. Clinical and experimental dermatology 1999, 24:2-6.

6. Anderson N: Hydroxyurea therapy: improving the lives of patients with sickle cell disease. Pediatric nursing 2006, 32:541-3.

7. Fathallah $\mathrm{H}$, Atweh GF: Induction of fetal hemoglobin in the treatment of sickle cell disease. Hematology/the Education Program of the American Society of Hematology American Society of Hematology 2006:58-62.

8. Lori F, Foli A, Kelly LM, Lisziewicz J: Virostatics: a new class of anti-HIV drugs. Current medicinal chemistry 2007, 14:233-41.

9. Mayhew C, Oakley O, Piper J, Hughes NK, Phillips J, Birch NJ, Elford HL, Gallicchio VS: Effective use of ribonucleotide reductase inhibitors (Didox and Trimidox) alone or in combination with didanosine (ddl) to suppress disease progression and increase survival in murine acquired immunodeficiency syndrome (MAIDS). Cell Mol Biol (Noisy-le-grand) 1997, 43:1019-29.

10. Mayhew CN, Sumpter R, Inayat M, Cibull M, Phillips JD, Elford HL, Gallicchio VS: Combination of inhibitors of lymphocyte activation (hydroxyurea, trimidox, and didox) and reverse transcriptase (didanosine) suppresses development of murine retrovirus-induced lymphoproliferative disease. Antiviral Res 2005, 65:13-22.

11. Rosenberger G, Fuhrmann G, Grusch M, Fassl S, Elford HL, Smid K, Peters GJ, Szekeres T, Krupitza G: The ribonucleotide reductase inhibitor trimidox induces c-myc and apoptosis of human ovarian carcinoma cells. Life sciences 2000, 67:3131-42.

12. Kaul DK, Kollander R, Mahaseth H, Liu XD, Solovey A, Belcher J, Kelm RJ Jr, Vercellotti GM, Hebbel RP: Robust vascular protective effect of hydroxamic acid derivatives in a sickle mouse model of inflammation. Microcirculation 2006, 13:489-97.

13. Balzarini J: Effect of antimetabolite drugs of nucleotide metabolism on the anti-human immunodeficiency virus activity of nucleoside reverse transcriptase inhibitors. Pharmacol Ther 2000, 87:175-87.

14. Foli A, Lori F, Maserati R, Tinelli C, Minoli L, Lisziewicz J: Hydroxyurea and didanosine is a more potent combination than hydroxyurea and zidovudine. Antiviral therapy 1997, 2:31-8

15. Gao WY, Cara A, Gallo RC, Lori F: Low levels of deoxynucleotides in peripheral blood lymphocytes: a strategy to inhibit human immunodeficiency virus type 1 replication. Proceedings of the National Academy of Sciences of the United States of America 1993, 90:8925-8.

16. Lori F, Foli A, Groff A, Lova L, Whitman L, Bakare N, Pollard RB, Lisziewicz J: Optimal suppression of HIV replication by low-dose hydroxyurea through the combination of antiviral and cytostatic ('virostatic') mechanisms. AIDS London, England 2005, 19:1173-81.

17. Perez-Simon JA, Sanchez-Abarca I, Diez-Campelo M, Caballero D, San Miguel J: Chronic graft-versus-host disease: Pathogenesis and clinical management. Drugs 2006, 66:1041-57.

18. Wysocki CA, Panoskaltsis-Mortari A, Blazar BR, Serody JS: Leukocyte migration and graft-versus-host disease. Blood 2005, 105:4191-9.

19. Kishimoto K, Furukawa K, Ashizuka S, Sawada T, Ayabe H: Profile of cytokine production during the inhibition of acute xenograft rejection. Surgery today 2000, 30:159-62.

20. Via CS, Finkelman FD: Critical role of interleukin-2 in the development of acute graft-versus-host disease. Int Immunol 1993, 5:565-72.

21. Garside P, Reid S, Steel M, Mowat AM: Differential cytokine production associated with distinct phases of murine graft-versus-host reaction. Immunology 1994, 82:211-4

22. De Wit D, Van Mechelen M, Zanin C, Doutrelepont JM, Velu T, Gerard C, Abramowicz D, Scheerlinck JP, De Baetselier P, Urbain J, et al: Preferential activation of Th2 cells in chronic graft-versus-host reaction. J Immunol 1993, 150:361-6.

23. Mohty M, Gaugler B: Inflammatory cytokines and dendritic cells in acute graft-versus-host disease after allogeneic stem cell transplantation. Cytokine Growth Factor Rev 2008, 19:53-63.
24. Lee $R$, Beauparlant $P$, Elford $H$, Ponka P, Hiscott J: Selective inhibition of I kappaB alpha phosphorylation and HIV-1 LTR-directed gene expression by novel antioxidant compounds. Virology 1997, 234:277-90.

25. Ito M, Shizuru JA: Graft-vs.-lymphoma effect in an allogeneic hematopoietic stem cell transplantation model. Biol Blood Marrow Transplant 1999, 5:357-68

26. Schmaltz C, Alpdogan O, Muriglan SJ, Kappel BJ, Rotolo JA, Ricchetti ET, Greenberg AS, Willis LM, Murphy GF, Crawford JM, van den Brink MR: Donor T cell-derived TNF is required for graft-versus-host disease and graft-versus-tumor activity after bone marrow transplantation. Blood 2003, 101:2440-5.

27. Yang $Y G$, Sykes $M$ : The role of interleukin-12 in preserving the graftversus-leukemia effect of allogeneic CD8 T cells independently of GVHD. Leukemia \& lymphoma 1999, 33:409-20.

28. Weiden PL, Sullivan KM, Flournoy N, Storb R, Thomas ED: Antileukemic effect of chronic graft-versus-host disease: contribution to improved survival after allogeneic marrow transplantation. The New England journal of medicine 1981, 304:1529-33.

29. Lori F: Hydroxyurea and HIV: 5 years later-from antiviral to immunemodulating effects. AIDS London, England 1999, 13:1433-42.

30. Benito JM, Lopez M, Lozano S, Ballesteros C, Gonzalez-Lahoz J, Soriano V: Hydroxyurea exerts an anti-proliferative effect on $T$ cells but has no direct impact on cellular activation. Clin Exp Immunol 2007, 149:171-7.

31. Raje N, Kumar S, Hideshima T, Ishitsuka K, Yasui H, Chhetri S, Vallet S, Vonescu E, Shiraishi N, Kiziltepe T, Elford HL, Munshi NC, Anderson KC Didox, a ribonucleotide reductase inhibitor, induces apoptosis and inhibits DNA repair in multiple myeloma cells. British journal of haematology 2006, 135:52-61.

32. Weinberg A: In vitro hydroxyurea decreases Th1 cell-mediated immunity. Clinical and diagnostic laboratory immunology 2001, 8:702-5.

33. Obara H, Nagasaki K, Hsieh CL, Ogura Y, Esquivel CO, Martinez OM, Krams SM: IFN-gamma, produced by NK cells that infiltrate liver allografts early after transplantation, links the innate and adaptive immune responses. Am J Transplant 2005, 5:2094-103.

34. Ioannidou E, Kao D, Chang N, Burleson J, Dongari-Bagtzoglou A: Elevated serum interleukin-6 (IL-6) in solid-organ transplant recipients is positively associated with tissue destruction and IL- 6 gene expression in the periodontium. Journal of periodontology 2006, 77:1871-8.

35. Cho WH, Kim HT, Sohn CY, Park CH, Park SB, Kim HC: Significance of IL-2, IL-2R, IL-6, and TNF-alpha as a diagnostic test of acute rejection after renal transplantation. Transplantation proceedings 1998, 30:2967-9.

36. Briscoe DM, Alexander SI, Lichtman AH: Interactions between T lymphocytes and endothelial cells in allograft rejection. Curr Opin Immunol 1998, 10:525-31.

37. Lalor PF, Adams DH: Lymphocyte homing to allografts. Transplantation 2000, 70:1131-9.

doi:10.1186/1476-9255-7-43

Cite this article as: Inayat et al:: Inhibition of allogeneic inflammatory responses by the Ribonucleotide Reductase Inhibitors, Didox and

Trimidox. Journal of Inflammation 2010 7:43.

\section{Submit your next manuscript to BioMed Central and take full advantage of:}

- Convenient online submission

- Thorough peer review

- No space constraints or color figure charges

- Immediate publication on acceptance

- Inclusion in PubMed, CAS, Scopus and Google Scholar

- Research which is freely available for redistribution

Submit your manuscript at www.biomedcentral.com/submit
Biomed Central 